\title{
KEBERADAAN TORTOR MARTUMBA PADA ETNIS BATAK TOBA DI PESISIR SIBOLGA
}

\author{
ELITA MANDAYARNI \\ Prodi Pendidikan Tari
}

\begin{abstract}
Tortor Martumba in Pesisir Sibolga is an entertainment dance in Toba Batak society in Independence Day event, welcoming important guests, to the entertainment and performing arts.This study examines the existence Tortor Martumba on ethnic Batak Toba in Pesisir Sibolga aim is to discuss about the existence, usability, functionality and form of presentation used .Teori theories related to the topic of research is the understanding of the existence, terms of usability, function theory and the theory of forms of presentation. The study was conducted in December 2015 through February 2016 in a village of the District Tukka Tukka Onan, and sample, including traditional leaders, artists in the District Middle Tapanuli. Data collection techniques including observation, interviews, literature study and documentation. Based on the results of research in the Coastal Sibolga Tortor Martumba that Tortor Martumba is Tortor of Batak Toba and danced by the Batak Toba ethnic communities in the Coastal Sibolga. This dance is there because people were resettled to the Batak Toba Coastal region Sibolga to continue to implement the customs they do in the place of origin is doing Tortor Martumba. Presence can be seen from the usability and functionality as entertainment welcoming distinguished guests, as an extracurricular learning materials in schools, as entertainment for the community as well as race. Tortor Martumba form of presentation can be seen from the simple movements and traditions that sombah movement, movement clapping, holding hands, jumping, lifting the legs, which is used Ulos clothing, makeup wearing natural makeup, singing music contained internal rhyme blared. In the presentation Tortor Martumba not use the theme, just do for entertainment.
\end{abstract}

Keywords: Presence, Presentation Form, Coastal Sibolga 


\section{PENDAHULUAN}

Indonesia merupakan Negara kepulauan yang terdiri dari beragam suku bangsa, bahasa serta budaya. Dimana puncak-puncak kebudayaan daerah ini akan membentuk kebudayaan nasional Indonesia. Kebudayaan terdiri dari beberapa aspek, salah satunya adalah kesenian, dimana tiaptiap daerah memiliki kesenian yang berbeda dengan daerah lainnya. Kesenian terdiri dari beberapa aspek yaitu seni rupa, seni music, seni tari. Dalah satu etnis yang berada di Sumatera Utara adalah etnis Batak Toba yang wilayahnya meliputi Balige, Porsea, Parsoburan, Laguboti, Ajibata, Uluan, Borbor, Lumban Julu,silindung, Samosir dan Humbang yang mempunyai beragam keseniansalah satunya adalah Tortor. Salah satu Tortor yang dilakukan secara turun temurun dari generasi ke generasi yaitu: Tortor Martumba. Martumba pada masa itu diyakini sebagai ritus atau media komunikasi doa (tonggo) yang ditujukan kepada opputa mula jadi na bolon (segala sumber yang ada) yang dilakukan sebagai ritual yang bertujuan memanggil hujan dengan menggunakan itak (tepung beras) pada malam hari diwaktu bulan tula atau rondang bulan (bulan purnama) dilaksanakan. Selain bertujuan emmanggil hujan? Martumba juga dapat menjadi media antara masyarakat sekitar dengan opputa mula jadi nabolon yang bertujuan untuk meminta berkat (pasu-pasu) atau rizky. Tortor Martumba dilakukan sambil bernyanyi yang berisi pantun bersahutsahutan sebagais arana untuk mengekspresikan dan mengkomunikasikan ekspresinya. Tortor Martumba juga ada di Pesisir Sibolga, kehadiran Tortor Martumba di bawa oleh masyarakat etnis Batak Toba yang berpindan dan melestarikan kesenian Tortor Martumba secara turun-temurun sebagai hiburan pada masa itu. Awal keberadaan masyarakat etnis Batak Toba dimulai sejak adanya interaksi antara masyarakat Batak Toba khusunya daerah Silindung dan Humbang yang berbatasan langsung denganKabupaten Tapanuli Tengah.yang rutin menukarkan hasi pertanian mereka dengan hasil laut masyarakat pesisir waktu itu. Akibat interaksi yang rutin dilakukan masyarakat Batak Toba akhirnya bertransmigrasi ke wilayah Kabupaten Tapanuli Tengah.tepatnya didaerah pegunungan, salah satunya di Desa Onan Tukka Kecamatn Tukka. Di daerah tersebut kebudayaan Batak Toba seperti Tortor Martumba sangat dilestarikan. Tortor Martumba muncul sekitar tahun 1940-an di tarikan oleh muda-mudi setempat pada 
malam hari saat terang bulan sebagai hiburan untuk menyambut kepulangan dan kepergian (laskar) pejuang yang berperang melawan penjajah waktu itu, sebagai rasa hormat dan syukur. Tarian ini di tampilkan di depan halaman rumah dengan pola membentuk lingkaran, gerakan sombah, bertepuk tangan, berpegangan tangan, melompat, mengangkat kaki. Tarian ini menggunakan musik internal. Umumnya syair-syair lagu yang dinyanyikan berisi (umpasa-umpasa) pantun berkesan religious dalam arti menekan hal-hal bersifat rahmad, karunia dan berkat. Untuk mengetahui lebih dalam lagi tentang Tortor Martumba penulis tertarik untuk meneliti tentang " Keberadaan Tortor Martumba pada etnis Batak Toba di Desa Onan Tukka Kecamatan Tukka Kabupaten Tapanuli Tengah”.

\section{Landasan Teori}

Untuk membahas Keberadaan Tortor Martumba penulis menggunakan teori keberadaan menurut Kamus Besar Bahasa Indonesia dan Indra Yuda, pengertian kegunaan menurut Kamus Besar Bahasa Indonesia, teori fungsi menurut Soedarsono, dan bentuk penyajian menurut Soedarsono dan Muhammad Jazuli

\section{Lokasi dan Waktu Penelitian}

Tempat dilaksanakannya penelitian adalah di Desa Onan Tukka Kecamatn Tukka Kabupaten Tapanuli Tengah.

\section{Teknik Analisis Data}

Penulis menganalisa da nmenguraikan data-data tersebut dengan menggunakan teknik kualitatif yaitu sebagai prosedur pemecahan masalah yang diselidiki dengan menggambarkan keadaaan objek penelitian pada saat sekarang Kabupaten Tapanuli Tengah.Waktu yang digunakan dalam penelitian ini untuk mendapatkan data yang dibutuhkan adalah selama tiga bulan yang akan dilaksakan pada Desember 2015 sampai Februari 2016.

\section{Populasi dan Sampel}

\section{Populasi}

Populasi dalam penelitian ini berjumlah tiga orang yaitu narasumber, tokoh adat, dan seniman.

\section{Sampel}

Sampel dalam penelitian ini berjumlah tiga orang yaitu narasumber, 
tokoh adat dan seniman yang ada di Kabupaten Tapanuli Tengah.

\section{Teknik Pengumpulan Data}

Teknik pengumpulan data yang dilakukan adalah sebagai berikut:

1. Studi kepustakaan

2. Observasi

3. Wawancara

4. Dokumentasi

\section{Isi}

Kabupaten Tapanuli Tengah adalah sebuah Kabupaten di Sumatera Utara. Ibu kotanya adalah Pandan. Terletak pada posisi $1^{\circ} .11^{\prime} .00^{\prime \prime}-2^{\circ} .22^{\prime} .0^{\prime \prime}$ LU dan 98 $.07^{\prime}$ '$98^{\circ} .12^{\prime}$ BT, Kabupaten Tapanuli Tengah sebagai Daerah Otonom dipertegas oleh Pemerintah dengan Undang-undang Nomor 7 Drt 1956 tentang Pembentukan Daerah Otonom Kabupaten-kabupaten dalam lingkungan Daerah Provinsi Sumatera Utara. Berdasarkan Peraturan Daerah Kabupaten Tapanuli Tengah Nomor 19 Tahun 2007 maka ditetapkan Hari Jadi Kabupaten Tapanuli Tengah adalah tanggal 24 Agustus 1945. Kabupaten Tapanuli Tengah terletak di Pesisir Pantai Barat Pulau Sumatera dengan panjang garis pantai $200 \mathrm{~km}$ dan wilayahnya sebagian besar berada di daratan Pulau Sumatera dan sebagian lainnya di pulau-pulau kecil dengan luas wilayah 2.188 $\mathrm{Km}^{2}$. Kabupaten Tapanuli Tengah sebagian besar berbukit - bukit dengan ketinggian 0 meter di atas permukaan laut. Dari seluruh wilayah Tapanuli Tengah, $43,90 \%$ berbukit dan bergelombang.

Batas wilayah bagian Utara berbatasan langsung dengan Kabupaten Aceh Singkil (Provinsi Aceh).

Bagian Selatan berbatasan langsung dengan Kabupaten Tapanuli Selatan.

Bagian Barat berbatasn langsung dengan Sibolga Kota dan Samudera Indonesia.

Bagian Timur berbatasan langsung dengan Kabupaten Tapanuli Utara, Kabupaten Humbang Hasudutan, Kabupaten Pakpak Bharat.

Penduduk Tapanuli Tengah tahun 2010 berjumlah sekitar 311.232 jiwa dengan kepadatan 136 jiwa per $\mathrm{km}^{2}$. Laju pertumbuhan periode tahun 2005-2010 sebesar $1,86 \%$ per tahun. Komposisi penduduk di Tapanuli Tengah yaitu 50,20\% laki-laki dan 49,80\% perempuan dengan beragam etnis mendiami daerah Kabupaten Tapanuli Tengah yaitu:

\begin{tabular}{|l|l|l|}
\hline No. & \multicolumn{1}{|c|}{ Etnis } & \multicolumn{1}{|c|}{$\%$} \\
\hline 1. & Batak Toba & $40 \%$ \\
\hline 2. & Padang & $20 \%$ \\
\hline 3. & Melayu & $10 \%$ \\
\hline 4. & Jawa & $5 \%$ \\
\hline
\end{tabular}




\begin{tabular}{|l|l|l|}
\hline 5. & Nias & $5 \%$ \\
\hline 6. & Madura & $5 \%$ \\
\hline 7. & Bugis & $10 \%$ \\
\hline 8 & Cina & $5 \%$ \\
\hline
\end{tabular}

10.1204000_2010

Tapanuli_Tengah dalam angka_2010. Pdf

Tabel 4.1 Persentasi masyarakat yang mendiami Kabupaten Tapanuli Tengah

Berdasarkan data tabel di atas mayoritas etnis yang mendiami wilayah ini adalah Etnis Batak Toba.

\section{Sejarah datangnya masyarakat etnis} Batak Toba di Pesisir Sibolga.

Awal kedatangan masyarakat etnis Batak Toba di wilayah Pesisir Sibolga sekitar abad ke-16, dimulai dengan cara berdagang (menjual hasil tanaman) dengan masyarakat Pesisir Sibolga waktu itu. Merekamulanya bermukim di wilayah pegunungan Humbang Hasudutan yangberdekatan dengan daerah Pesisir Sibolga khususnya daerah Kabupaten Tapanuli Tengah. Humbang Hasudutan dahulunya termasuk dalam wilayah Tapanuli Utara tapi sejak mengalami pemekaran tahun 2013 Humbang Hasudutan menjadi sebuah Kabupaten baru. Humbang Hasundutan memiliki 10 Kecamatan, 1 Kelurahan dan 143 Desa berada di jajaran Bukit Barisan dengan keadaan Tanah umumnya bergelombang yang merupakan Daerah Aliran Sungai (DAS) untuk beberapa kabupaten : Dairi, Tapanuli Tengah dan Toba Samosir, dari Humbang Hasudutan masyarakat Batak Toba menuju daerah Kabupaten Tapanuli Tengah tepatnya di kecamatan Sitahuis, untuk lebih mempermudah jalur perdagangannya. Seiring berjalannya waktu rutinitas yang dilakukan semakin berkembang, terlebih lagi masyarakat Batak Toba lainnya ikut bertransmigrasi, dan ada pula yang menikah dengan masyarakat pesisir sehingga, masyarakat Batak Toba semakin berkembang dan menyebar ke daerah lainnya di Pesisir Sibolga.

Keberadaan Tortor Martumba pada etnis Batak Toba di Pesisir Sibolga

\section{Tortor Martumba}

Dahulunya Tortor Martumba di lakukan sebagai ritual mangido udan (meminta hujan)yang dilakukan oleh para muda mudi di Samosir. Berdasarkan (wawancara dengan Nurtjimahati Boru Sitompul). Keberadaan Martumba serta fungsinya tergantung pada daerah yang melaksanakannya. Misalnya di Tarutung, masyarakat melaksanakan Martumba pada acara-acara besar di gerja dan disekolah 
dilaksanakan pada hari kemerdekaan, di Pahae masyarakat melaksanakan Martumbauntuk ajang pencarian jodoh bagi muda mudi, belajar adat dan pengumpulan dana.

Pada kasus ini penulis melakukan penelitian Martumba di Desa Onan Tukka Kabupaten Tapanuli Tengah. Di Desa Onan Tukka telah cukup lama mengenal Martumba. Martumba di laksanakan para muda mudi pada malam hari sebagai hiburan dan untuk menyambut kehadiran dan juga kepergian laskar (pejuang) yang berperang melawan penjajah waktu itu dengan tujuan menyampaikan doa dan juga ucapan rasa syukur terhadap opputa mula jadi na bolon (segala sumber yang ada) kegiatan ini rutin dilakukan oleh masyarakat Batak Toba sebagai rasa penghormatan dan ikatan kekeluargaan yang kuat kepada sesamanya. Dalam Martumba terdapat lagu atau syairsyair yang isinya melambangkan semangat perjuangan, permohonan dan ungkapan hati. Tortor Martumba termasuk tari yang mentradisi di kalangan masyarakat Batak Toba di Pesisir Sibolga, syair-syair yang dinyanyikan oleh penari tidak selamanya sama, tergantung situasi dan kondisi dalam rangka apa tarian itu dilakukan. Seiring perkembangan zaman Tortor Martumba tidak lagi dilakukan pada malam hari sekarang sudah berubah fungsi menjadi hiburan dalam rangka menyambut Hari Kemerdekaan RI, menyambut kedatangan para pejabat daerah (tamu terhormat), dan sebagai ajang pertunjukan seni.

\section{Kegunaan Tortor Martumba}

Kegunaan Tortor Martumba sebagai materi pembelajaran di sekolah yang bermanfaat sebagai penambah keterampilan khusus bagi siswa dalam mempelajari sebuah tari. Manfaat mempelajari Tortor Martumba bagi anak-anak sanggar adalah sebagai media hiburan dan sebagai pertunjukan yang di garap untuk di pertontonkan yang dipersiapkan dengan baik mulai dari latihan hingga pementasan. Tortor Martumba juga bermanfaat sebagai hiburan bagi masyarakat itu sendiri yang bermakna kekompakan dan ikatan kekeluargaan dapat dilihat dari gerakan berpegangan tangan dan bergenggaman tangan.

\section{Fungsi Tortor Martumba}

1. Tortor Martumba sebagai sarana upacara persembahan dan pemujaan yang dahulunya di lakukan masyarakat Batak Toba di daerah asalnya untuk mangido udan (meminta hujan) kepada opputa 
mula jadi na bolon (segala sumber yang ada).

2. Tortor Martumba sebagai sarana pertunjukan pada event-event besar seperti Festival, perlombaan 17an, HUT daerah setempat dengan maksud agar lebih mengingat, mengenang dan mencintai budaya sendiri terlebih lagi zaman yang sudah semakin berkembang dan kesenian daerah yang hampir punah.

3. Tortor Martumba sebagai sarana hiburan yang di lakukan oleh masyarakat setempat untuk menunjukkan kebersamaan, kekompakan dalam ikatan kekeluargaan.

\section{Bentuk Penyajian}

\section{Gerak}

Gerakan yang dilakukan tidak berubah dari dahulu sampai sekarang, dan yang membedakan hanya syair yang di nyanyikan oleh penari dan gerakan yang ada pada Tortor Martumba sangat sederhana yaitu somba adat,somba adat marhaliang, tangan martoppak dohot mangakkat pat margotti gotti, manggatukkon tangan tu siamun tu siambirang dohot pat mangalakka, marsitiopan tangan, manggomgom tangan tu jolo, sombahraja singgang, gerakan yang dilakukan secara serentak dan berirama sesuai dengan syair pantun yang di nyanyikan.

\section{Ragam gerak Tortor Martumba}

Gerakan somba adat

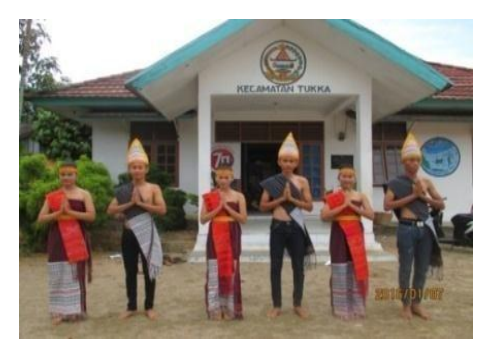

Gerakan somba adat marhaliang

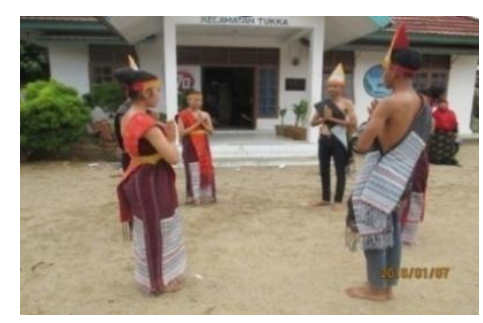

Gerakan Martopak tangan mangakkat pat margotti-gotti dohot mangahormat
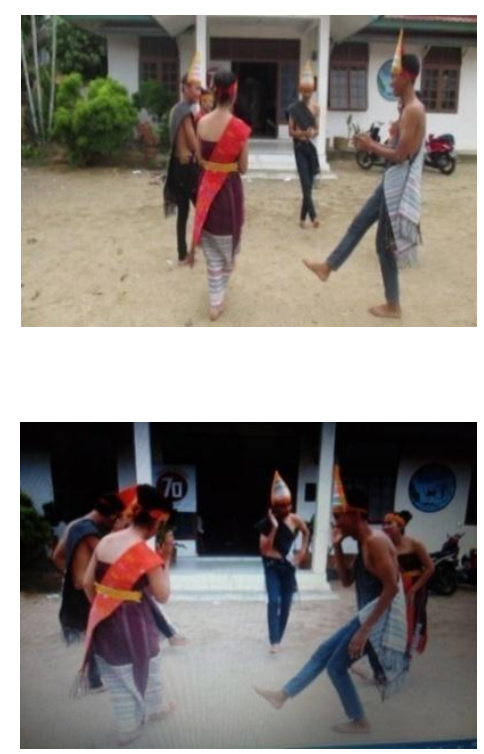
Gerakan manganggutton tangan tu siamun tu hambirang dohot pat mangalakka tu jolo

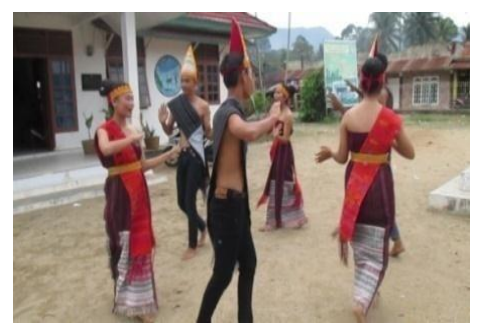

Gerakan Marsitiopan tangan marhaliang, mardalan tu jolo dohot tu pudi
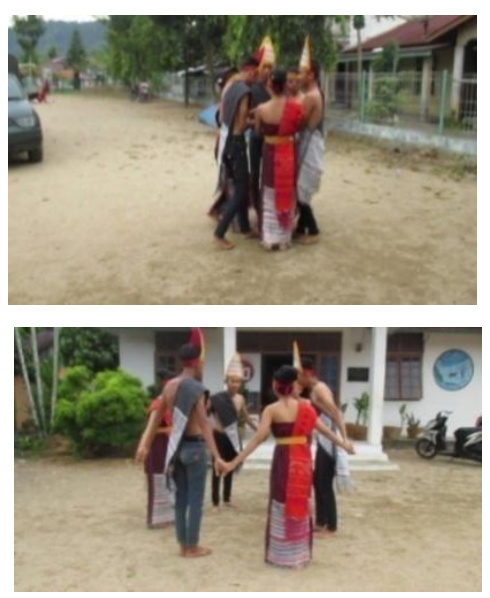

Gerakan martopak tangan marhaliang

Pr: tortor raja dhot singgang

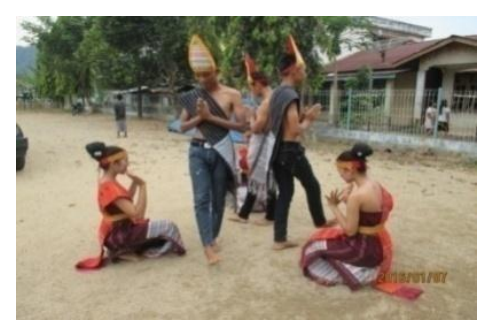

\section{Tata Busana}

Pada Tortor Martumba, busana yang digunakan sangatlah sederhana sama seperti yang ada di daerah asalnya yaitu memakai kain ulos.Ulos adalah kain tenun khas Batak, yang secara harfiah berati selimut yang menghangatkan tubuh; melindungi dari terpaan udara dingin. Ulos bisa merankan berbagai fungsi sandang, sebagai selendang, sarung, penutup kepala, dan lain sebagainya.Ulos dianggap sebagai peninggalan leluhur orang Batak, yang merupakan bangsa yang hidup di datarandataran tinggi pegunugan. Dengan maksud tetap menjaga tubuh tetap hangat, kain Ulos mereka kenakan untuk menghalau dingin selama mereka berladang dan beraktivitas lainnya.

\section{Tata rias}

Untuk Tortor Martumba make up natural di pilih sebagai penunjang penampilannya, agar terlihat lebih sederhana dan mentradisi.

\section{Musik Pengiring}

Pada Tortor Martumba musik iringan yang digunakan musik jenis internal, musik yang berasal dari penari, yaitu bernyanyi berbentuk (umpasa) pantun, bertepuk tangan dan menghentakkan kaki. Logat syair yang di nyanyikan sudah berubah di karenakan masyarakat Batak toba yang sudah berbaur dengan masyarakat pesisir sehingga keaslian tidak lagi terlihat. 


\section{Penutup}

\section{Kesimpulan}

Dari hasil penelitian yang dilakukan di lapangan dan penejelasan yang sudah di uraikan mulai dari latar belakang hingga pembahasan, maka dapat disimpulkan secara keseluruhan terhadap Tortor Martumbadi Desa Onan Tukka Kabupaten Tapanuli Tengah adalah sebagai berikut.

1. Tarian ini termasuk tarian yang berasal dari Batak Toba yang sudah lama ada, tarian ini ada di daerah Pesisir Sibolga di bawa oleh masyarakat etnis Batak Toba, tarian ini di adakan dengan tujuan untuk mengingat kenangan di daerah asalnya dan untuk melestarikan kesenian milik mereka itu sendiri agar tidak punah seiring kemajuan zaman, tarian ini bersifat hiburan yang di tarikan oleh muda-mudi suku Batak Toba. Gerakan pada Tortor Martumba ini masih memakai gerakan sederhana yaitu gerakan sombah, gerakan bertepuk tangan, bergenggaman tangan, mengehentakkan kaki. Gerakan yang dilakukan serentak sesuai dengan syair lagunya.
2. Musik iringan pada tarian adalah musik internal, musik. musik yang berasal dari penari. Seperti nyanyian, tepuk tangan, hentakan kaki dan syair yang di nyanyikan berisi umpasa (pantun) yang bersahut sahutan.

3. Busana dan rias yang digunakan pada tarian ini sangat tradisional sama seperti yang ada di Batak Toba.

\section{Saran}

Dari hasil kesimpulan penelitian diatas, maka dapat diajikan beberpa saran antara lain sebagai berikut :

1. Penulis berharap semoga Tortor Martumba ini tetap selalu di lestarikan agar tidak punah dan hilang seiring perkembangan zaman.

2. Diharapkan kepada masyarakat Pesisir Sibolga Kabupaten Tapanuli Tengah khususnya kepada pemerintah daerah agar senantiasa memperkenalkan berbagai tari-tarian kepada masyarakat luas baik lokal maupun diluar daerah dan mengadakan pertunjukkan tarian ini agar dapat memahami bahwa 
keseniaan baik secara bentuk geraknya hingga makna yang ingin disampaikan akan tersampaikan kepada penikmat seni maupun masyarakat yang menyaksikanya.

3. Dengan meningkatkan kepedulian terhadap kesenian daerah, berarti telah menyelamatkan anak cucu kita dari pengaruh budaya luar yang akan merusak budaya sendiri.

4. Semoga penelitian ini dapat memberikan pengetahuan baru bagi masyarakat setempat sebagaimana Keberadaan Tortor Martumba di daerah Pesisir Sibolga.

\section{Daftar Pustaka}

Arikunto, Suharsimi. 2008. Prosedur Penelitian. Jakarta: Rieneke Cipta.

Hutapea, Bilferi. 2007. Fungsi Martumba bagi masyarakat Batak Toba di Pahae: kajian folklor.Skripsi.Etnomusikologi.Univ ersitas Sumatera Utara.

Jazuli, Muhammad. 1994. Tari: telaah teoritis. Jakarta: Balai Pustaka.
Kaelan.2012. Pendidikan Kewarganegaraan untuk Perguruan Tinggi.Paradigma Indonesia.

Koentjaraningrat. 2009. Pengantar Ilmu Antropologi. Jakarta: Rieneka Cipta.

Mardiana, Alita. 2008. Kajian Makna Simbol Gerak Dasar Tortor Batak Toba. Skripsi. Sendratasik. Fakultas Bahasa dan Seni. Universitas Negeri Medan.

Obri, Elvia, Siburian. 2008. Tortor Martumba pada masyarakat Batak Toba di Kabupaten Samosir.Skripsi Sendratasik. Fakultas Bahasa dan Seni Universitas Negeri Medan.

Pardosi. 2008. Makna Simbol Umpasa, Sinamot yang ada dalam etnis Batak Toba seperti Umpasa (pantun) dan Sinamot (Mahar).Jurnal.

Etnomusikologi.Universitas Sumatera Utara.

Poerdarminta, W.J.S 1966. Kamus Besar Bahasa Indonesia. Jakarta: Balai Pustaka.

Ranny,Prayetty Melina. 2007. Bentuk Tortor Martumba Pada Masyarakat Batak Toba di Kabupaten Samosir. Skripsi Sendratasik. Fakultas Bahasa dan Seni. Universitas Negeri Medan.

Ruslan, Rosadi. 2003.Metode Penelitian Public Relation dan Komunikasi, Jakarta: Raja Grafindo Persada 
